ignored unless the sampling fraction exceeds $5 \%$ to $10 \%{ }^{1}$ Ignoring $\mathrm{fpc}$ with high sampling fractions overestimates the standard error. If the objective of a study is to conduct observations or a survey in a small department, failure to consider sampling fraction would produce overestimates of sample size required, because the standard error is overestimated. A common approach to sample-size calculation for proportional data is $n=z^{2} p q / d^{2}$ where $z$ is a specified number of standard deviations and $d$ is the absolute difference (precision) to be detected. Note that this formula does not consider population size. For example, a sample of size 100 would be specified to generate a $95 \%$ confidence interval for $\mathrm{p}=0.5$ and $\mathrm{d}=0.1$, regardless of population size. If this meant drawing 100 observations from thousands of events, that makes sense. For example, asking in what proportion of patient encounters staff wash their hands suggests an infinite population of potential future encounters to observe. But what if the question were the proportion of department members who comply with policy (an observation study) or who agree with policy (a survey study) in a small department? Would it make sense to suggest observing or surveying 100 employees in a department that employs 10 people? Sample size in a finite population can be adjusted by applying the fpc as $n^{\prime}=n /(1+n / N)$. In this case, $100 /(1+100 / 10)$ suggests that just 9 of the 10 people need to be studied. Correction of this nature has been incorporated in published tables for survey sampling. ${ }^{2,3}$

When infection surveillance results consider any particular group of patients or period of time as a sample representative of all groups or periods, then the fpc may be ignored. When overall compliance is evaluated by surveillance of encounters, as in covert observation studies of gloving or handwashing, fpc may be ignored. However, when a finite number of staff members are surveyed for knowledge or opinion, or when staff rather than encounters are the sampling unit for compliance studies, then fpc may be important and should not be ignored.

\section{REFERENCES}

1. Cochrane WG. Sampling Techniques. New York, NY: John Wiley \& Sons; 1977.

2. Bird FE Jr, Loftus RG. Lo\$\$ Control Management. Loganville, GA: Institute Press; 1976.

3. Zikmund WG. Business Research Methods. 5th ed. Fort Worth, TX: Dryden Press; 1997.

\title{
Antimicrobial Resistance and Genomic Diversity of Escherichia coli From Urinary Tract Infections
}

\section{Gina Pugliese, RN, MS Martin S. Favero, PhD}

Perrin and colleagues from the Laboratory of Bacteriology and Virology, CHU Pontchaillou, Rennes, France, report a study of welldefined community- and nosocomially acquired isolates of Escherichia coli responsible for urinary tract infections. The isolates were studied for their resistance to $\beta$-lactams, quinolones, and co-trimoxazole, antibiotics widely used for treatment of urinary infections. For each strain, an antibiogram was obtained using the
Vitek automat (bioMérieux Inc, St Louis, MO), which estimates the minimal inhibitory concentrations of various drugs.

The results showed that nosocomial strains were significantly more amoxicillin-resistant than community strains and were also significantly more resistant to co-trimoxazole and first-generation quinolones than the latter. To determine whether this was due to transmission of strains within the hospital, DNA restriction patterns established using $X b a \mathrm{I}$ enzyme and separation by pulsed-field gel electrophoresis were compared. Extreme genomic diversity was found among both the community and nosocomial strains. The authors concluded that the increased frequency of resistance among nosocomial strains is thus not due to transmission of resistant hospital strains but probably results from the selection of resistant strains from the endogenous flora of patients.

FROM: Perrin M, Donnio PY, Heurtin-Lecorre C, Travert MF, Avril JL. Comparative antimicrobial resistance and genomic diversity of Escherichia coli isolated from urinary tract infections in the community and in hospitals. $J$ Hosp Infect 1999;41: 273-279. 